do as well. Limited mobility is red flag, and patients who exhibit it should be considered a greater-risk population.

\section{References}

1. Nishimura RA, Otto CM, Bonow RO, Carabello BA, Erwin JP III, Fleisher LA, et al. 2017 AHA/ACC focused update of the 2014 AHA/ACC guideline for the management of patients with valvular heart disease: a report of the American College of Cardiology/American Heart Association task force on clinical practice guidelines. J Am Coll Cardiol. 2017;70:252-89.

2. Baumgartner H, Falk V, Bax JJ, De Bonis M, Hamm C, Holm PJ, et al. 2017 ESC/ EACTS guidelines for the management of valvular heart disease. Eur Heart J. 2017;38:2739-91.

3. Afilalo J, Sharma A, Zhang S, Brennan JM, Edwards FH, Mack MJ, et al. Gait speed and 1-year mortality following cardiac surgery: a landmark analysis from the Society of Thoracic Surgeons adult cardiac surgery database. J Am Heart Assoc. 2018;7:e010139.

4. Alfredsson J, Stebbins A, Brennan JM, Matsouaka R, Afilalo J, Peterson ED, et al. Gait speed predicts 30-day mortality after transcatheter aortic valve replacement: results from the Society of Thoracic Surgeons/American College of Cardiology transcatheter valve therapy registry. Circulation. 2016;133:1351-9.

5. Kano S, Yamamoto M, Shimura T, Kagase A, Tsuzuki M, Kodama A, et al. Gait speed can predict advanced clinical outcomes in patients who undergo transcath- eter aortic valve replacement: insights from a Japanese multicenter registry. Circ Cardiovasc Interv. 2017;10(9):e005088.

6. Van der Wulp K, van Wely MH, Schoon Y, Vart P, Olde Rikkert MGM, Morshuis WJ, et al. Geriatric assessment in the prediction of delirium and long-term survival after transcatheter aortic valve implantation. J Thorac Cardiovasc Surg. 2021;161:2095-102.e3.

7. Hyman MC, Vemalapalli S, Szeto WY, Stebbins A, Patel PA, Matsouaka RA, et al. Conscious sedation versus general anesthesia for transcatheter aortic valve replacement: insights from the national cardiovascular data registry Society of Thoracic Surgeons/American College of Cardiology transcatheter valve therapy registry. Circulation. 2017;136:2132-40.

8. Villablanca PA, Mohananey D, Nikolic K, Bangalore S, Slovut DP, Mathew V, et al. Comparison of local versus general anesthesia in patients undergoing transcatheter aortic valve replacement: a meta-analysis. Catheter Cardiovasc Interv. 2018;91:330-42.

9. Attizzani GF, Patel SM, Dangas GD, Szeto WY, Sorajja P, Reardon MJ, et al. Comparison of local versus general anesthesia following transfemoral transcatheter self-expanding aortic valve implantation (from the transcatheter valve therapeutics registry). Am J Cardiol. 2019;123:419-25.

10. Bilotta F, Lauretta MP, Borozdina A, Mizikov VM, Rosa G. Postoperative delirium: risk factors, diagnosis and perioperative care. Minerva Anestesiol. 2013;79:1066-76.

11. Chaput AJ, Bryson GL. Postoperative delirium: risk factors and management: continuing professional development. Can J Anaesth. 2012;59:304-20.

\title{
Commentary: Recalibrating the eyeball test
}

\author{
Jason P. Glotzbach, MD, and Craig H. Selzman, MD
}

Although surgeons have been in the tricky business of risk assessment since Halstead, perhaps never in surgical history has preoperative patient selection and counseling been more central to decision-making than in the age of catheter-based structural heart interventions. In this issue of the Journal, ${ }^{1}$ van der Wulp and colleagues offer another contribution to this evolving clinical paradigm. In a prospectively gathered cohort of 511 elderly patients with aortic stenosis, formalized geriatric assessment provided granular preoperative data on patient characteristics including cognitive,

From the Division of Cardiothoracic Surgery, University of Utah, Salt Lake City, Utah.

Disclosures: Dr Glotzbach has received speaker fees from Edwards Lifesciences. Dr Selzman has nothing to disclose with regard to commercial support.

Received for publication March 11, 2020; accepted for publication March 12, 2020; available ahead of print March 19, 2020.

Address for reprints: Jason P. Glotzbach, MD, Division of Cardiothoracic Surgery, University of Utah, 30 North 1900 East, SOM 3C-127, Salt Lake City, UT 84132 (E-mail: jason.glotzbach@hsc.utah.edu).

J Thorac Cardiovasc Surg 2021;161:2106-7

$0022-5223 / \$ 36.00$

Copyright (c) 2020 by The American Association for Thoracic Surgery

https://doi.org/10.1016/j.jtcvs.2020.03.018

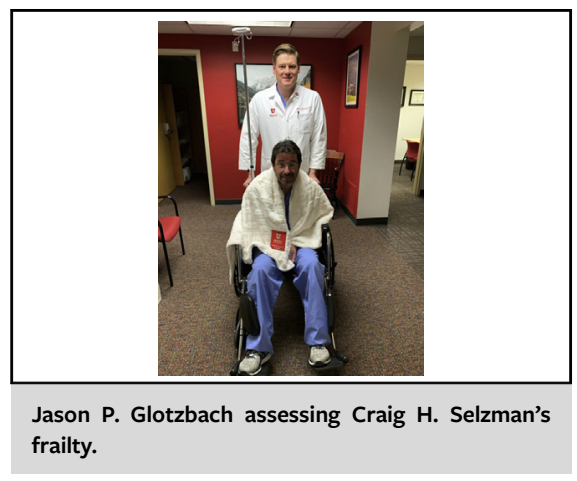

CENTRAL MESSAGE

Quantitative assessment of preoperative frailty is critical for patients undergoing transcatheter valve procedures to identify patients at high risk for postoperative delirium and poor outcomes.

functional, and nutritional status before transcatheter aortic valve replacement (TAVR). They found that impaired preoperative mobility predicted a greater risk of postoperative delirium and decreased 2-year survival from $91.4 \%$ to 
$79.4 \%$, thus confirming what we all intuitively suspect to be true-patients in worse physical shape before surgery tend to have worse outcomes.

There are several problems with this study that limit the generalizability to the broader TAVR patient population; all of the cases were performed with general anesthesia and most via transaxillary access $(71.4 \%)$, which is not the predominant practice pattern at most high-volume centers. As the authors acknowledge, it is certainly possible that patients undergoing transfemoral access using conscious sedation would have had different contributors to postoperative delirium.

While this study does not provide a genuine "a-ha" moment, it does underscore the need for surgeons to remain involved in the risk assessment and patient-selection process. The original trial design for TAVR rightly included a mandatory heart team concept that started with patient risk assessment. ${ }^{2}$ Now that conclusive evidence of the early safety and effectiveness of TAVR has been established, it is crucial for all members of the heart team to continue diligent work to refine the perioperative risk-assessment process. At our institution, we routinely involve the geriatrics and palliative care service in the preoperative discussions with patients in the valve clinic and test mobility with the 5-meter walk test.

The risk assessment process should be standardized using objective reproducible metrics. Although clinician experience and subjective evaluation certainly play a role, the accuracy of even experienced clinicians to predict outcomes lags more refined tools. For example, Jain and colleagues ${ }^{3}$ demonstrated that surgeons overestimate risk in low risk patients but underestimate risk in high-risk patients. Frailty is known to predict poor outcomes following TAVR. ${ }^{4}$ The Valve Academic Research Consortium-2 consensus document highlights the need for formal frailty testing in addition to the STS preoperative risk score, but there is not an agreed-on objective metric for mobility. ${ }^{5}$ The "timed up and go" test, which van der Wulp and colleagues used in this study, is a validated metric to quantify functional mobility in elderly patients. ${ }^{6}$ Quantitative metrics such as these are indispensable in building reliable clinical protocols and pathways. Although we surgeons should never discount the importance of our own eyeballs, perioperative risk should be assessed using a quantitative multidisciplinary approach that will facilitate optimal outcomes for these challenging patients.

\section{References}

1. Van der Wulp K, van Wely MH, Schoon Y, Vart P, Olde Rikkert MGM Morshuis WJ, et al. Geriatric assessment in the prediction of delirium and longterm survival after transcatheter aortic valve implantation. J Thorac Cardiovasc Surg. 2021;161:2095-102.e3.

2. Smith CR, Leon MB, Mack MJ, Miller DC, Moses JW, Svensson LG, et al. Transcatheter versus surgical aortic-valve replacement in high-risk patients. $N$ Engl J Med. 2011;364:2187-98

3. Jain R, Duval S, Adabag S. How accurate is the eyeball test? A comparison of physician's subjective assessment versus statistical methods in estimating mortality risk after cardiac surgery. Circ Cardiovasc Qual Outcomes. 2014;7: 151-6.

4. Rogers T, Alraies MC, Moussa Pacha H, Bond E, Buchanan KD, Steinvil A, et al. Clinical frailty as an outcome predictor after transcatheter aortic valve implantation. Am J Cardiol. 2018;121:850-5.

5. Kappetein AP, Head SJ, Généreux P, Piazza N, van Mieghem NM, Blackstone EH et al. Updated standardized endpoint definitions for transcatheter aortic valve implantation: the valve academic research consortium-2 consensus document. $J$ Thorac Cardiovasc Surg. 2013;145:6-23.

6. Podsiadlo D, Richardson S. The timed "Up \& Go": a test of basic functional mobility for frail elderly persons. J Am Geriatr Soc. 1991;39:142-8. 